\title{
The occurrence, types, consequences and preventability of in-hospital adverse events - a scoping review
}

\author{
René Schwendimann ${ }^{1,2^{*}}$, Catherine Blatter ${ }^{2}$, Suzanne Dhaini ${ }^{2,3}$, Michael Simon ${ }^{2,4}$ and Dietmar Ausserhofer ${ }^{2,5}$
}

\begin{abstract}
Background: Adverse events (AEs) seriously affect patient safety and quality of care, and remain a pressing global issue. This study had three objectives: (1) to describe the proportions of patients affected by in-hospital AEs; (2) to explore the types and consequences of observed AEs; and (3) to estimate the preventability of in-hospital AEs.

Methods: We applied a scoping review method and concluded a comprehensive literature search in PubMed and CINAHL in May 2017 and in February 2018. Our target was retrospective medical record review studies applying the Harvard method-or similar methods using screening criteria-conducted in acute care hospital settings on adult patients ( $\geq 18$ years).

Results: We included a total of 25 studies conducted in 27 countries across six continents. Overall, a median of 10\% patients were affected by at least one AE (range: 2.9-21.9\%), with a median of 7.3\% (range: 0.6-30\%) of AEs being fatal. Between 34.3 and $83 \%$ of AEs were considered preventable (median: $51.2 \%$ ). The three most common types of AEs reported in the included studies were operative/surgical related, medication or drug/fluid related, and healthcareassociated infections.

Conclusions: Evidence regarding the occurrence of AEs confirms earlier estimates that a tenth of inpatient stays include adverse events, half of which are preventable. However, the incidence of in-hospital AEs varied considerably across studies, indicating methodological and contextual variations regarding this type of retrospective chart review across health care systems. For the future, automated methods for identifying AE using electronic health records have the potential to overcome various methodological issues and biases related to retrospective medical record review studies and to provide accurate data on their occurrence.
\end{abstract}

Keywords: Adverse events, Patient safety, Medical error, Hospitals, Scoping review

\section{Background}

Adverse events (AEs) seriously affect patient safety and quality of care in hospitals. The epidemiology of harm due to medical care remains a pressing issue on a global scale. In the US, a recent report reviewing earlier studies ranked iatrogenic causes, especially medical errors, as the third leading cause of death [1]. Specifically, up to $1.1 \%$ of hospital admissions led to deaths due to medical errors. Extrapolating this percentage to the annual

\footnotetext{
* Correspondence: rene.schwendimann@usb.ch

${ }^{1}$ University Hospital Basel, Patient Safety Office, Spitalstr. 22, 4031 Basel, Switzerland

${ }^{2}$ Department Public Health Institute of Nursing Science, University of Basel, Basel, Switzerland

Full list of author information is available at the end of the article
}

patient numbers for all registered US hospitals, this would account for more than 400,000 deaths in 2013 alone. While such a high volume of patient harm associated with hospital care is shocking, the projected annual cost of measurable medical errors is mind-boggling: in the US alone, based on data from that year, AEs have been dubbed "the 17.1 billion dollar problem" [2].

The two most frequent classes of $\mathrm{AE}$, postoperative infections and pressure ulcers, accounted for the largest annual costs (6.5 billion USD). Following these, central venous catheter infections and infections following infusions, injections and similar procedures resulted in a combined total of more than one billion USD in extra healthcare costs.

(c) The Author(s). 2018 Open Access This article is distributed under the terms of the Creative Commons Attribution 4.0 International License (http://creativecommons.org/licenses/by/4.0/), which permits unrestricted use, distribution, and 
The authors conclude that the most frequent errors result from rather common medical services for which cost-cutting efforts compromise patient safety [2]. That is, the majority of medical errors leading to in-hospital AEs are not caused by poorly performing physicians, nurses, or other clinicians. More commonly, they arise from care delivery problems that result from conditions at the levels of the individual patient or staff member, the task or the health care team. They may even be rooted in the overall work environment. If safeguards along this causal pathway fail, AEs can result. Thus, current, accurate information on AEs is crucial both for individual learning and for improving and developing more reliable health care systems [3].

Despite the existence of various national AE registries, such as the US Food and Drug Administration's system for voluntary reporting of serious drug- or medical device-related AEs [4], or the Dutch Healthcare Inspectorate for mandatory reporting of sentinel events [5], comprehensive, prospective national-level data on in-hospital AEs are severely limited [1]. Thus, the available evidence is based mainly on retrospective chart review studies aimed at detecting $\mathrm{AE}$ occurrences. The two most frequently used review methods are the "Harvard method' [6] and the Institute of Healthcare Improvement's Global Trigger Tool [7]. Both involve two-stage medical record reviews and were designed to provide data on the frequency and types of AEs. Stage 1, an evaluation of the presence of certain screening criteria-triggers-is followed by a more in-depth manual review of the medical record to detect an $\mathrm{AE}$ (Stage 2). Table 1 provides a brief overview of the characteristics and differences between the two methods [8].
The Global Trigger Tool (GTT) has the demonstrated advantage of identifying AEs more accurately than other readily available methods, including voluntary reporting of critical incidents or the Patient Safety Indicators put forth by the Agency for Healthcare Research and Quality [9]. Consequently, it has become an increasingly popular method for post hoc safety measurement and monitoring [10]. In a recent systematic review on 48 general inpatient studies using the GTT, rates of AEs varied between 7 and $40 \%$. Of those identified, the most common event types were complications related to infections, surgical procedures and medication [11]. An earlier systematic review [12] indicated similar findings in eight studies, including a total of more than 70,000 hospital inpatient records, using the Harvard method or comparable approaches. Their analyses revealed that nearly every 10th patient was affected by an adverse event, of which $43 \%$ were deemed preventable, and $7.4 \%$ were lethal. This time, the majority of AEs were related to surgical procedures (39.6\%) and medications (15.1\%), while medical procedure- (7.8\%), diagnostic- (7.5\%) and therapeutic-related $(7 \%)$ events were less frequent, they remained noteworthy [12].

Despite increasing interest among clinical practitioners and researchers to further investigate and develop the GTT, e.g., studies of the accuracy of automated methods for identifying AEs from electronic health record data $[13,14]$, retrospective chart review methods such as the Harvard method remain widely used to identify AEs [8]. In particular, these have been used in large-scale studies to estimate national-level AE prevalence. As a consequence, since de Vries's 2008 systematic review on the topic,

Table 1 Brief overview on the characteristics and differences between the 'Harvard method' and the 'Global Trigger Tool method' to detect AEs through retrospective medical record review based on Unbeck et al. [8]

\begin{tabular}{|c|c|c|}
\hline Characteristics & Harvard method & Global Trigger Tool \\
\hline Definition of $\mathrm{AE}$ & $\begin{array}{l}\text { "An unintended injury or } \\
\text { complication that results } \\
\text { in disability at discharge, } \\
\text { death or prolonged hospital } \\
\text { stay and is caused by } \\
\text { healthcare management } \\
\text { rather than the patient's } \\
\text { underlying disease." }\end{array}$ & $\begin{array}{l}\text { "Unintended injury resulting } \\
\text { from or contributed to } \\
\text { by medical care that } \\
\text { requires additional } \\
\text { monitoring, treatment } \\
\text { or hospitalization, } \\
\text { or that results in death." }\end{array}$ \\
\hline Focus & Omission and commission & $\begin{array}{l}\text { Commission, excludes } \\
\text { omission }\end{array}$ \\
\hline Method & $\begin{array}{l}\text { Two - three stage } \\
\text { retrospective record review }\end{array}$ & $\begin{array}{l}\text { Two stage retrospective } \\
\text { record review }\end{array}$ \\
\hline Review Stage 1 & $\begin{array}{l}\text { One healthcare professional } \\
\text { (most often nurse) }\end{array}$ & $\begin{array}{l}\text { Two independent reviewers } \\
\text { per record (e.g. nurse, physician) }\end{array}$ \\
\hline Review Stage 2 & $\begin{array}{l}\text { Two independent reviews } \\
\text { (most often physicians) }\end{array}$ & $\begin{array}{l}\text { A team discuss the findings } \\
\text { together Physician as arbitrator }\end{array}$ \\
\hline Criterion/Trigger & $\begin{array}{l}\text { - Comprehensive reading of record } \\
\text { - Screening for one of } 18 \text { broad criteria }\end{array}$ & $\begin{array}{l}\text { - No comprehensive reading } \\
\text { - First screening for one of } 54 \text { triggers }\end{array}$ \\
\hline Number of records / Time & Random, large samples & $\begin{array}{l}\text { Random, small samples (e.g. } 10 \text { records } \\
\text { every second week or } 20 \text { records } \\
\text { every month per hospital) }\end{array}$ \\
\hline
\end{tabular}


numerous retrospective chart review studies have applied Harvard-style methodologies [9].

\section{Methods}

Aim

The purpose of this study was to update recent in-hospital adverse event figures according to three objectives: (1) to describe the proportions of patients affected by in-hospital AEs; (2) to report the types and consequences of observed AEs; and (3) to estimate the preventability of in-hospital AEs.

\section{Design}

We conducted a scoping review based on the framework outlined by Arksey and O'Malley [15]. A scoping review's purpose is to summarize "a range of evidence in order to convey the breadth and depth of a field" [16]. It differs from a systematic literature review in that it requires broader research aims (as opposed to a narrowly focused question) and more refined post hoc (rather than a priori) selection criteria for papers during the review process, but suspends critical appraisal of bias risk or other quality indicators until after the selection process is complete [15, 17-19].

\section{Literature search}

A first literature search of the Medline (PubMed) and CINAHL databases was conducted in May 2017 using the terms "Incidence" [tiab] AND "adverse events" [tiab] AND "patient safety." The records retrieved were screened independently by CB and SD for hospital adverse event studies conducted between 1991 and 2017. A manual search of the returned articles' bibliographies was also performed to identify additional relevant studies. In February 2018, in line with our scoping review methodology, a second comprehensive database search was conducted to confirm and complement the results of the first PubMed literature search using an elaborate search string using Hausner et al.'s approach: ((adverse [tiab] AND events [tiab] AND patient*[tiab]) OR incidents [tiab]) AND preventable [tiab])) [20]. Following Hausner et al.'s model, we developed our search string based on a primary set of relevant records (a development set) identified in the first search. The relevant records' titles and abstracts contained keywords (e.g., $\mathrm{MeSH}$ terms) and free text terms that served as the building blocks of the final search string. Variations of the search string were then tested against a second set of relevant records (validation set). In our case, as no $\mathrm{MeSH}$ term for "adverse events" existed and no promising alternative keywords could be identified, a free text only search string was compiled. All records retrieved were screened independently by RS and DA (see Fig. 1).

\section{Study selection}

In order to reliably compare the data, we defined an $\mathrm{AE}$ according to the Harvard Medical Practice Study definition: "an unintended injury or complication that results in disability at the time of discharge, death or prolonged hospital stay caused by health care management rather than by the patient's underlying disease process" [21]. All primary studies that (1) used this or a similar definition of an AE, (2) applied a retrospective medical record review according to the Harvard method or a similar method, (3) used a two-stage record review with primary criteria-driven screening by trained reviewers (mostly nurses) and a secondary review of their findings by a physician, (4) were conducted in acute care hospital settings (e.g., medical, surgical, ICU), and (5) included hospitalized adult patients ( $\geq 18$ years), were eligible for inclusion. Studies restricted to specific clinical areas (e.g., pediatrics, emergency department), studies from non-acute care settings (e.g., rehabilitation, long-term care, primary care), as well as those that evaluated only specific types of AE (e.g., adverse drug events), were excluded. Systematic reviews or studies applying prospective methods (e.g., critical incident reporting systems) were also excluded. Likewise, given that differences in review methodologies result in disparities in AE detection [8], and that a systematic literature review on the application of the GTT had recently been published [11], studies applying the GTT method were excluded. Final inclusion of studies was achieved by consensus between the authors (RS and DA).

\section{Data charting and analysis}

From the selected studies, we extracted information on the prevalence (i.e., the proportion of affected patients), types, frequencies, and related consequences of AEs, those AEs' preventability, and relevant study details (i.e., methods, number of hospitals, setting and sample size) (see Table). Critical appraisal of the included studies and meta-analysis of $\mathrm{AE}$ rates across studies were not undertaken due to methodological heterogeneity (e.g., differences in setting, retrospective chart review methods, number of screening criteria, number of reviewers, detection and inclusion of AEs before index admission). Medians and ranges of occurrence, types, consequences and preventability of AEs were calculated using Microsoft Office Excel 2016.

\section{Results}

\section{Study selection}

We included 25 studies conducted between 1991 and 2017 in 27 countries in Europe, Asia, Africa, North and South America, and Australia/New Zealand (see Table 2). All included studies used two-stage retrospective medical record reviews to detect in-hospital AEs based on the 'Harvard method' [6] or modified 


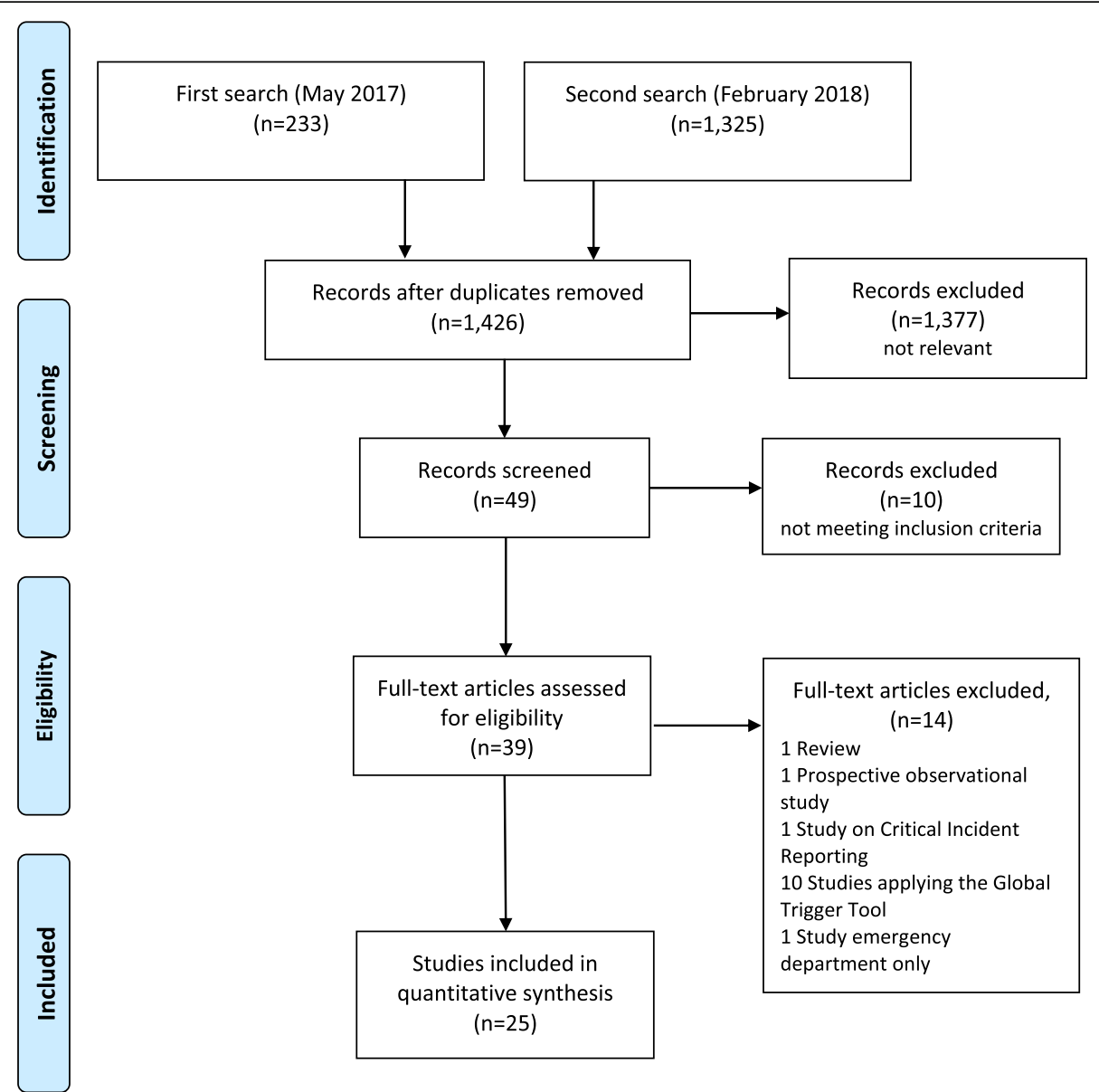

Fig. 1 Flow diagram of article retrieval

versions of it, such as those developed in Canada [22] and the United Kingdom [23]. Of the 25 studies used, 19 were multi- and 6 single-centre studies. In the multicentre studies, the number of hospitals ranged from two to 58, with sample sizes ranging from 354 [24] to 30,121 [6] patients/records. The single-centre studies' samples ranged from 500 [25] to 1501 [26] patients/records (see Table 2).

\section{Frequencies of AEs}

Across all studies, the frequencies of patients with AEs spanned between $2.9 \%$ [27] and 21.9\% [28]. The overall median was $10 \%$, with multicentre studies showing a median of 9.3\% (range: $2.9 \%$ [27] - 21.9\% [28]). Single centre studies reported a median of $11.2 \%$ with an overall range of 3.3\% [26] to $13.5 \%$ [29] patients affected by AEs.

\section{Types of AEs}

The most common and most consistently reported types of $\mathrm{AE}$ in the included studies were operative/surgical-related events, often resulting from procedural complications and injuries such as post-op bleeding or return to surgery. These accounted for a median of $40 \%$ of those detected (range: $27 \%$ [30] - 74.9\% [28]). The second most frequent type was medication- or drug/fluid-related events such as medication errors, which accounted for a median of $19.3 \%$ of those detected (Range: 4\% [31] - 73\% [25]). In third position, healthcare-associated infections and allergic reactions were responsible for a median of $17.7 \%$ of all detected events (Range: 0.2\% [28] - 25.3\% [32]).

\section{Severity and preventability of AEs}

AEs' consequences were mostly temporary and minimal (recuperation < 1 month) (Median: 53.5\%; Range: 16.1\% [33] $-73.4 \%$ [34]) or caused no patient harm. However, $21.2 \%$ of those affected suffered from moderate impairment (recuperation 1-12 months) (Range: 4.1\% [30] $56.5 \%$ [33]). A median of $7.3 \%$ of AEs resulted in permanent disability $(<50 \%$ and $>50 \%$ disability) (Range: $3.9 \%$ [34] - 17\% [28]). Death occurred in a median of 7.3\% of patients affected by at least one AE (Range: 0.6\% [35] - 30\% [31]). Across all included studies, a median of $51.2 \%$ of events were considered preventable (Range: $34.3 \%$ [34] - 83\% [31]). In the reviewed studies, an $\mathrm{AE}$ 


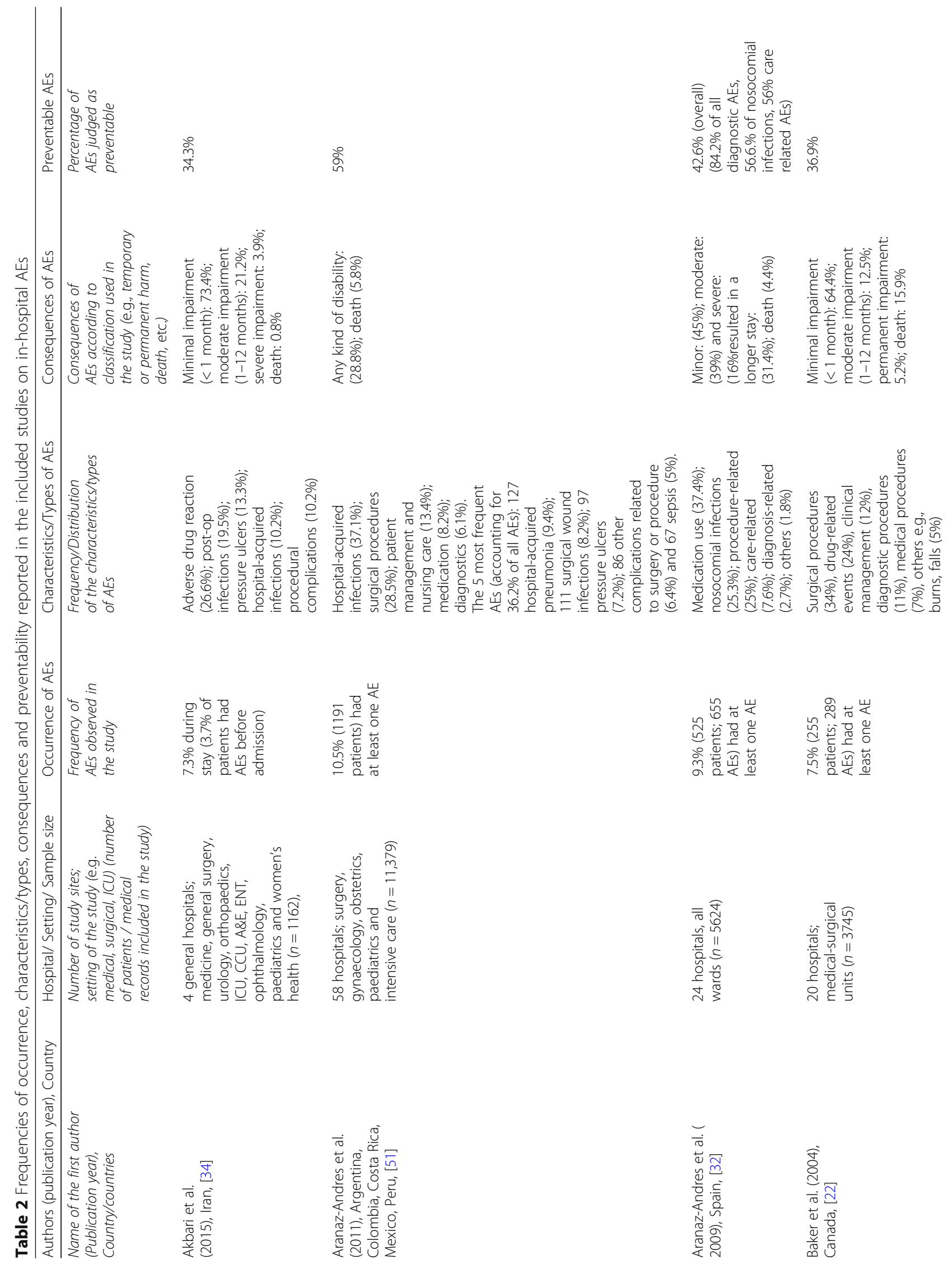




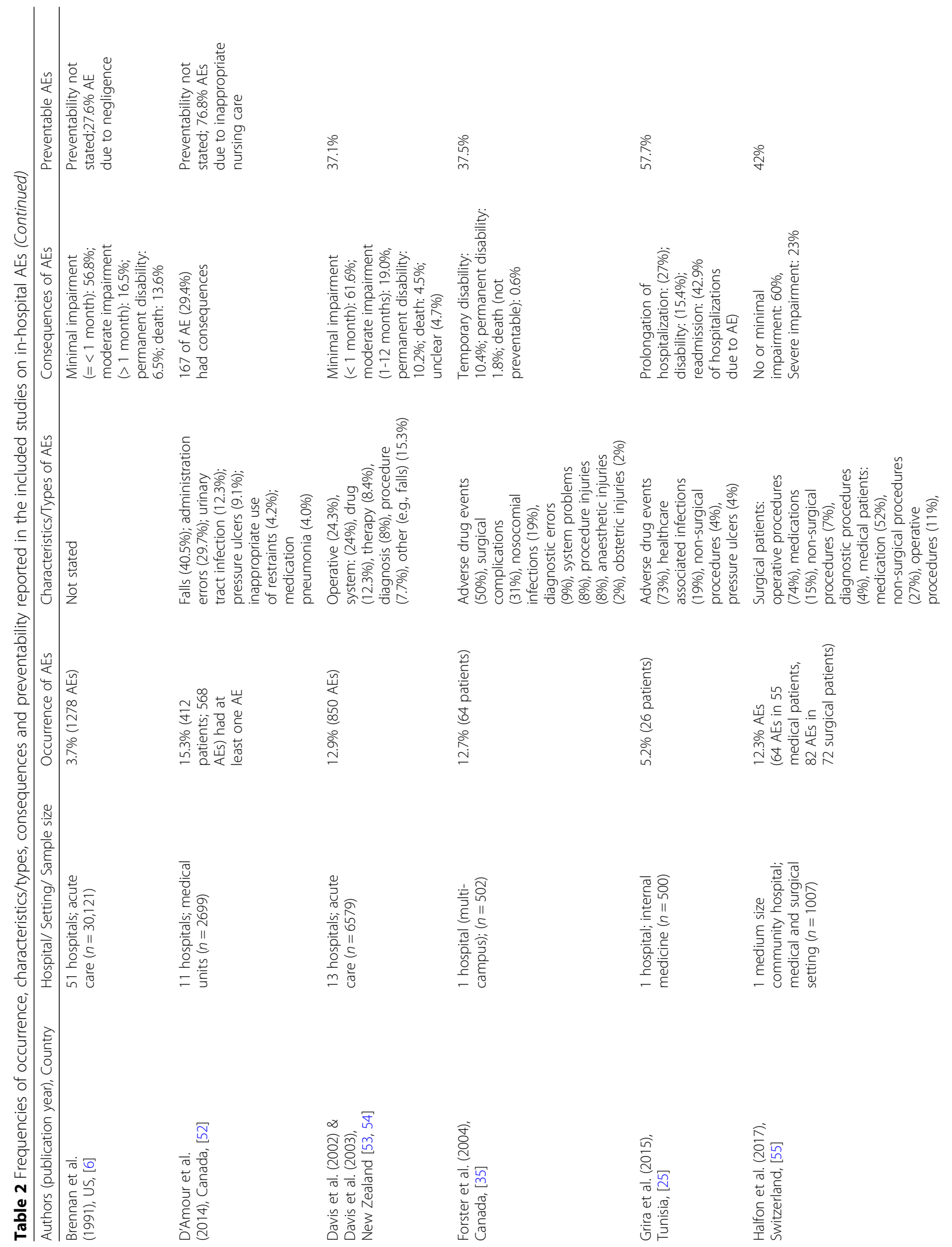




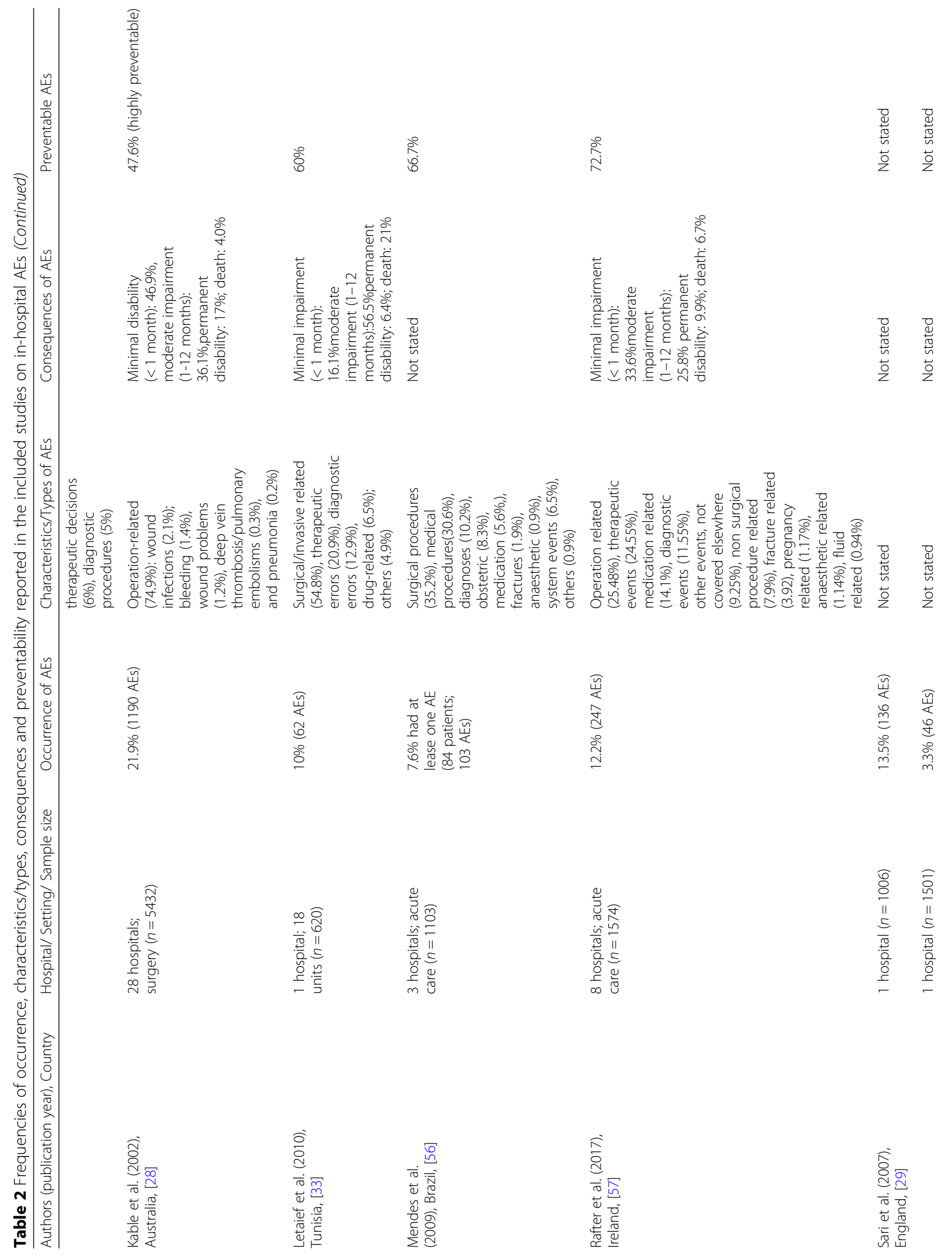




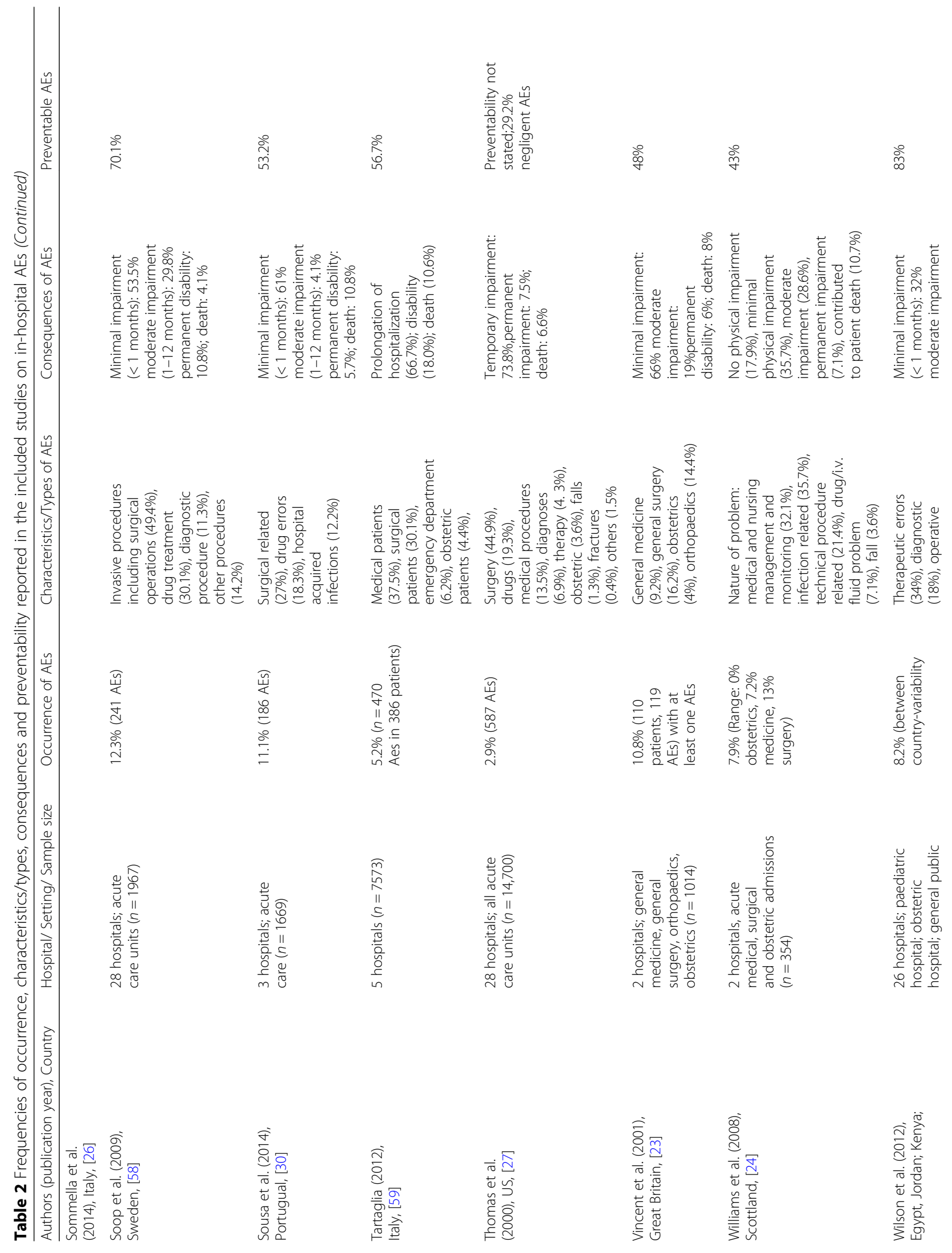




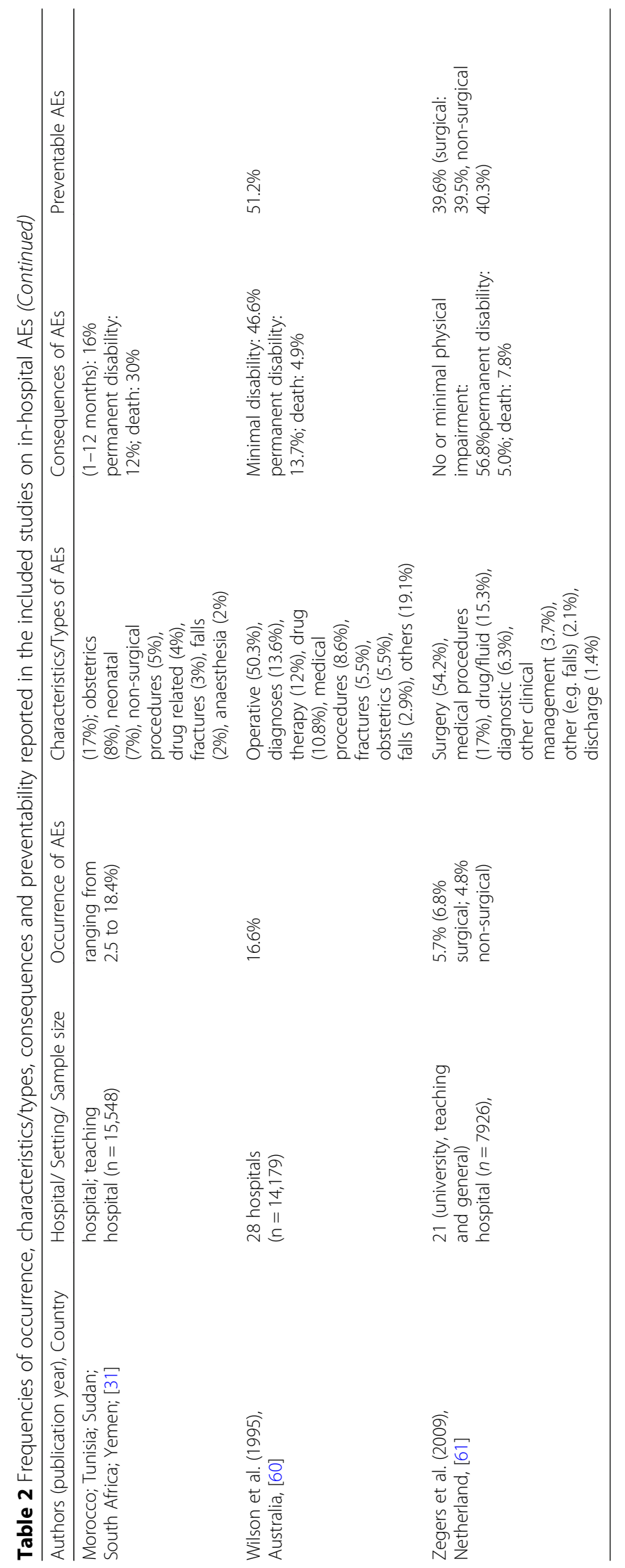


was classified as preventable based on the chart reviewer's professional judgement of the given incident and consent. In most of the selected studies, preventability of AEs was determined based on a 6-point scale range from "virtually no evidence of preventability" (1 point) to "virtually certain evidence of preventability" (6 points), with a cut-off score of 4 .

\section{Discussion}

We conducted a scoping review and provided an updated international overview of studies on the prevalence, characteristics/types, consequences and preventability of reported hospital AEs. Included studies that applied a retrospective chart review methodology based on the 'Harvard Medical Practice Study' approach or similar methods published after 2008 confirmed the findings of de Vries et al.'s systematic review on the worldwide magnitude of in-hospital AEs [12]: one out of ten hospitalized patients is affected by at least one AE, with one out of 14 such events resulting in fatality and half of all cases considered preventable. These findings on AEs' occurrence are comparable to those reported in studies either applying the Global Trigger Tool methodology [11] or relying on patients' reports of having experienced medical errors [36]. Applying these figures to the Swiss context in 2015 [37] would mean that roughly 140,500 in-patients in Swiss hospitals experienced AEs, resulting in about $9^{\prime} 400$ fatalities.

Although we included studies that used similar definitions for AEs and retrospective record review methodologies similar to the Harvard Medical Practice Study [38], the occurrence of in-hospital AEs varied considerably across studies. A number of methodological differences including setting/sample (e.g., medical and/or surgical patients), inclusion of events before or after index admission, the number and types of screening criteria, thresholds for defining causation and preventability or the number, professional background, and the chart reviewers' level of experience [39, 40], may partly account for the variability observed in in-hospital AEs across countries. It must be acknowledged that retrospective record review methodology is at risk of bias, including hindsight and performance bias, which would lead respectively to over- or underestimation. However, reducing methodological heterogeneity is crucial to achieving accurate comparisons between countries and meta-analyses of AE rates across studies. The development of a reporting guideline on retrospective chart review studies, e.g., based on the "Strengthening the Reporting of Observational Studies in Epidemiology" (STROBE) statement [41], could contribute to standardization of the performance and reporting of AE studies.
Moreover, contextual factors within healthcare systems, such as variation in the quality and methods of medical and patient record documentation across countries and hospitals, might be a key source of variation in $\mathrm{AE}$ detection. In combination with the GTT, electronic health records (EHR) are currently gaining the interest of researchers and clinical practitioners alike, as they offer tremendous opportunities to develop automated AE identification methods [14]. While such an approach appears to be time-saving and less resource intensive compared to manual retrospective record review, it demands consistent documentation and representation of key EHR data elements. However, using machine learning and natural language processing in electronic health records, the possibilities to detect and monitor AEs are expanding rapidly. The most advanced systems are already providing real-time feedback to healthcare professionals, thereby offering hospitals advanced quality improvement and learning opportunities [42]. While the results obtained via EHR analyses are surprisingly similar to those available via manual review, computerized searches are virtually instantaneous and cost very little after the initial infrastructure is in place.

Despite variations between in-hospital $\mathrm{AE}$ incidence and measurement, our findings confirm both AEs' harmful impacts on patients and the persistent need for effective preventive measures. As noted above, the three main types of AEs reported in the included studies were related to surgery, medication/drugs and healthcare-associated infections. In recent years, the study of quality improvement interventions has led to major progress in patient safety [43], with evidence on effective strategies readily available [44]. For example, hospitals can adopt individual or bundled interventions. Adapted from aviation industry methodology, these are aimed at reducing the three major types of AEs, and include the use of checklists in the operating room [45], care bundles for the insertion of central venous catheters [46, 47], hand hygiene adherence [48], and medication reconciliation practices [49]. Acute care hospitals need to utilize comprehensive and balanced frameworks such as those available to measure, monitor [50] and improve care safety, as well as to foster a culture of safety, especially concerning the three main AE types. Accurate monitoring of in-hospital AEs, including via retrospective record reviews, is essential for the implementation and evaluation of evidence-based strategies to reduce their occurrence and patient harm.

\section{Limitations}

This scoping review should be read in view of certain limitations. First, we conducted our literature search in the two major electronic databases, Medline (Pubmed) and CINAHL, but did not search for "gray" literature. Therefore, additional relevant studies might have been 
missed. Second, in line with the scoping review methodology, we did not assess the included studies' risk of bias. Although we observed methodological heterogeneity in the included studies we did not include/exclude studies based on a quality assessment, as would be necessary in a systematic review. Therefore, caution is advised when drawing conclusions based on these studies' combined data.

\section{Conclusions}

This scoping review included 25 studies conducted in 27 countries. All had applied the 'Harvard Method' of detecting AEs. The median overall occurrence was $10 \%$. Of this number, half were regarded as preventable and $7.3 \%$ led to fatal outcomes. However, the occurrence of in-hospital AEs varied considerably across studies, indicating methodological variation and cultural/contextual differences in conducting this type of retrospective chart review. Further research, such as on automated methods of identifying AEs in electronic health records, is needed to overcome methodological issues and bias related to this type of retrospective medical record review and to provide accurate data on their occurrence. As the three most common and most consistently reported types of in-hospital AEs were related to surgery, medication and nosocomial infections, further efforts to measure and monitor these three areas will make hospital care safer and more reliable.

\section{Abbreviations}

AE: Adverse events; EHR: Electronic Health Record; GTT: Global Trigger Tool; ICU: Intensive care Unit; MeSH: Medical Subject Headings

\section{Acknowledgements}

The authors would like to thank Natascha Baumann and Marian Struker for tabulating the reviewed studies and Chris Shultis for professional editing of the manuscript. The authors would like to thank Dr. Natasha Rafter for providing additional information to their study.

\section{Availability of data and materials}

The data supporting our findings are included in the published article.

\begin{abstract}
Authors' contributions
RS: conceptualization and study design, formulation of search strategies; screening of titles, abstracts and full texts; planning of the analysis and interpretation of data; quality assessment; writing of the manuscript. CB: literature search; screening of titles, abstracts and full texts; and data acquisition. SD: literature search; screening of titles, abstracts and full texts; and data acquisition. MS: interpretation of data; quality assessment. DA: supervision of the study including review methodology, data extraction, data analysis, writing of the manuscript. All authors read and approved the final version of the manuscript to be published.
\end{abstract}

\section{Competing interests}

All authors declare that they have no competing interests.

Ethics approval and consent to participate

Not applicable.

\section{Consent for publication}

Not applicable.

\section{Publisher's Note}

Springer Nature remains neutral with regard to jurisdictional claims in published maps and institutional affiliations.

\section{Author details}

'University Hospital Basel, Patient Safety Office, Spitalstr. 22, 4031 Basel, Switzerland. ${ }^{2}$ Department Public Health Institute of Nursing Science, University of Basel, Basel, Switzerland. ${ }^{3}$ American University of Beirut, School of Nursing, Beirut, Lebanon. Inselspital Bern University Hospital, Nursing Research Unit, Bern, Switzerland. ${ }^{5}$ College of Health Care-Professions Claudiana, Bozen, Italy.

Received: 18 March 2018 Accepted: 27 June 2018

Published online: 04 July 2018

\section{References}

1. Makary MA, Daniel M. Medical error-the third leading cause of death in the US. BMJ. 2016;353:i2139.

2. Van Den Bos J, Rustagi K, Gray T, Halford M, Ziemkiewicz E, Shreve J. The $\$ 17.1$ billion problem: the annual cost of measurable medical errors. Health Aff (Millwood). 2011;30(4):596-603.

3. Taylor-Adams S, Vincent C. Systems analysis of clinical incidents: the London protocol. Clinical Risk. 2004;10(6):211-20.

4. U.S. Food and Drug Administration. Reporting serious problems to FDA. https://www.fda.gov/MedicalDevices/default.htm. Accessed 2 July 2018.

5. Leistikow I, Mulder S, Vesseur J, Robben P. Learning from incidents in healthcare: the journey, not the arrival, matters. BMJ Quality \&amp;amp; Safety. 2017;26(3):252.

6. Brennan TA, Leape LL, Laird NM, Hebert L, Localio AR, Lawthers AG, Newhouse JP, Weiler PC, Hiatt HH. Incidence of adverse events and negligence in hospitalized patients. Results of the Harvard medical practice study I. N Engl J Med. 1991;324(6):370-6.

7. Griffin FA, Resar RK. IHI global trigger tool for measuring adverse events (second edition). IHI innovation series white paper. In., second Edi edn. Cambridge: Institute for Healthcare Improvement; 2009.

8. Unbeck M, Schildmeijer K, Henriksson P, Jurgensen U, Muren O, Nilsson L, Pukk Harenstam K. Is detection of adverse events affected by record review methodology? An evaluation of the "Harvard medical practice study" method and the "global trigger tool". Patient Saf Surg. 2013;7(1):10.

9. Classen DC, Resar R, Griffin F, Federico F, Frankel T, Kimmel N, Whittington JC, Frankel A, Seger A, James BC. 'Global trigger tool' shows that adverse events in hospitals may be ten times greater than previously measured. Health Aff (Millwood). 2011;30(4):581-9.

10. Doupi P, Svaar H, Bjørn B, Deilkås E, Nylén U, Rutberg H. Use of the global trigger tool in patient safety improvement efforts: Nordic experiences. Cogn Tech Work. 2014;17(1):45-54.

11. Hibbert PD, Molloy CJ, Hooper TD, Wiles LK, Runciman WB, Lachman P, Muething SE, Braithwaite J. The application of the global trigger tool: a systematic review. Int J Qual Health Care. 2016;28(6):640-9.

12. de Vries EN, Ramrattan MA, Smorenburg SM, Gouma DJ, Boermeester MA. The incidence and nature of in-hospital adverse events: a systematic review. Qual Saf Health Care. 2008;17(3):216-23.

13. Musy SN, Ausserhofer D, Schwendimann R, Rothen HU, Jeitziner MM, Rutjes AW, Simon M. Trigger tool-based automated adverse event detection in electronic health records: systematic review. J Med Internet Res. 2018;20(5):e198.

14. Rochefort CM, Buckeridge DL, Tanguay A, Biron A, D'Aragon F, Wang S, Gallix B, Valiquette L, Audet LA, Lee TC, et al. Accuracy and generalizability of using automated methods for identifying adverse events from electronic health record data: a validation study protocol. BMC Health Serv Res. 2017; 17(1):147.

15. Arksey H, O'Malley L. Scoping studies: towards a methodological framework. Int J Soc Res Methodol. 2005;8(1):19-32.

16. Armstrong R, Hall BJ, Doyle J, Waters E, Update C. 'Scoping the scope' of a cochrane review. J Public Health (Oxf). 2011;33(1):147-50.

17. Levac D, Colquhoun H, O'Brien KK. Scoping studies: advancing the methodology. Implement Sci. 2010;5:69.

18. Kastner M, Tricco AC, Soobiah C, Lillie E, Perrier L, Horsley T, Welch V, Cogo E, Antony J, Straus SE. What is the most appropriate knowledge synthesis method to conduct a review? Protocol for a scoping review. BMC Med Res Methodol. 2012;12(1):114. 
19. Daudt HM, van Mossel C, Scott SJ. Enhancing the scoping study methodology: a large, inter-professional team's experience with Arksey and O'Malley's framework. BMC Med Res Methodol. 2013;13(1):48.

20. Hausner E, Waffenschmidt S, Kaiser T, Simon M. Routine development of objectively derived search strategies. Syst Rev. 2012;1:19.

21. Brennan TA, Leape LL, Laird NM, Hebert L, Localio AR, Lawthers AG, Newhouse GP, Weiler PC, Hiatt HH. Incidence of adverse events and negligence in hospitalized patients. N Engl J Med. 1991;325(3):210.

22. Baker GR, Norton PG, Flintoft V, Blais R, Brown A, Cox J, Etchells E, Ghali WA, Hebert P, Majumdar SR, et al. The Canadian adverse events study: the incidence of adverse events among hospital patients in Canada. CMAJ. 2004;170(11):1678-86.

23. Vincent C, Neale G, Woloshynowych M. Adverse events in British hospitals: preliminary retrospective record review. BMJ. 2001;322(7285):517-9.

24. Williams DJ, Olsen S, Crichton W, Witte K, Flin R, Ingram J, Campbell MK, Watson M, Hopf $Y$, Cuthbertson BH. Detection of adverse events in a Scottish hospital using a consensus-based methodology. Scott Med J. 2008; 53(4):26-30

25. Grira M, Larbi T, El Ouni A, Bouslama K, Abdallah M, Harmel A, Hamzaoui S, M'Rad S. The incidence of serious adverse events in a tunisian hospital: a retrospective medical record review study. Tunis Med. 2015;93(12):795-9.

26. Sommella L, de Waure C, Ferriero AM, Biasco A, Mainelli MT, Pinnarelli L, Ricciardi W, Damiani G. The incidence of adverse events in an Italian acute care hospital: findings of a two-stage method in a retrospective cohort study. BMC Health Serv Res. 2014;14:358.

27. Thomas EJ, Studdert DM, Burstin HR, Orav EJ, Zeena T, Williams EJ, Howard KM, Weiler PC, Brennan TA. Incidence and types of adverse events and negligent care in Utah and Colorado. Med Care. 2000;38(3):261-71.

28. Kable AK, Gibberd RW, Spigelman AD. Adverse events in surgical patients in Australia. Int J Qual Health Care. 2002;14(4):269-76.

29. Sari AB, Sheldon TA, Cracknell A, Turnbull A, Dobson Y, Grant C, Gray W, Richardson A. Extent, nature and consequences of adverse events: results of a retrospective casenote review in a large NHS hospital. Qual Saf Health Care. 2007;16(6):434-9.

30. Sousa P, Uva AS, Serranheira F, Nunes C, Leite ES. Estimating the incidence of adverse events in Portuguese hospitals: a contribution to improving quality and patient safety. BMC Health Serv Res. 2014;14:311.

31. Wilson RM, Michel P, Olsen S, Gibberd RW, Vincent C, El-Assady R, Rasslan O, Qsous S, Macharia WM, Sahel A, et al. Patient safety in developing countries: retrospective estimation of scale and nature of harm to patients in hospital. BMJ. 2012;344:e832.

32. Aranaz-Andres JM, Aibar-Remon C, Vitaller-Burillo J, Requena-Puche J, TerolGarcia E, Kelley E. Gea-Velazquez de Castro MT, group Ew: impact and preventability of adverse events in Spanish public hospitals: results of the Spanish National Study of adverse events (ENEAS). Int J Qual Health Care. 2009;21(6):408-14

33. Letaief M, El Mhamdi S, El-Asady R, Siddiqi S, Abdullatif A. Adverse events in a Tunisian hospital: results of a retrospective cohort study. Int J Qual Health Care. 2010;22(5):380-5.

34. Akbari Sari A, Doshmangir L, Torabi F, Rashidian A, Sedaghat M, Ghomi R, Prasopa-Plaizier N. The incidence, nature and consequences of adverse events in Iranian hospitals. Arch Iran Med. 2015;18(12):811-5.

35. Forster AJ, Asmis TR, Clark HD, Al Saied G, Code CC, Caughey SC, Baker K, Watters J, Worthington J, Van Walraven C. Ottawa Hospital patient safety study: incidence and timing of adverse events in patients admitted to a Canadian teaching hospital. CMAJ. 2004;170:1235-40.

36. Schwappach DL. Risk factors for patient-reported medical errors in eleven countries. Health Expect. 2014;17(3):321-31.

37. Bundesamt für Gesundheit. Kennzahlen der Schweizer Spitäler 2015. Bern: Bundesamt für Gesundheit; 2017.

38. Brennan TA, Leape LL, Laird NM, Hebert L, Localio AR, Lawthers AG, Newhouse JP, Weiler PC, Hiatt HH, Harvard Medical Practice Study I. Incidence of adverse events and negligence in hospitalized patients: results of the Harvard medical practice study I. Qual Saf Health Care 2004. 1991; 13(2):145-51. discussion 151-142

39. Runciman WB, Webb RK, Helps SC, Thomas EJ, Sexton EJ, Studdert DM, Brennan TA. A comparison of iatrogenic injury studies in Australia and the USA. II: reviewer behaviour and quality of care. Int J Qual Health Care. 2000; 12(5):379-88.

40. Thomas EJ, Studdert DM, Runciman WB, Webb RK, Sexton EJ, Wilson RM Gibberd RW, Harrison BT, Brennan TA. A comparison of iatrogenic injury studies in Australia and the USA. I: context, methods, casemix, population, patient and hospital characteristics. Int J Qual Health Care. 2000;12(5):371-8.

41. von Elm E, Altman DG, Egger M, Pocock SJ, Gotzsche PC, Vandenbroucke $J P$, Initiative S. The strengthening the reporting of observational studies in epidemiology (STROBE) statement: guidelines for reporting observational studies. PLoS Med. 2007:4(10):e296.

42. Li Q, Melton K, Lingren T, Kirkendall ES, Hall E, Zhai H, Ni Y, Kaiser M, Stoutenborough L, Solti I. Phenotyping for patient safety: algorithm development for electronic health record based automated adverse event and medical error detection in neonatal intensive care. J Am Med Inform Assoc. 2014;21(5):776-84

43. Portela MC, Pronovost PJ, Woodcock T, Carter P, Dixon-Woods M. How to study improvement interventions: a brief overview of possible study types. BMJ Qual Saf. 2015;24(5):325-36.

44. Shekelle PG, Pronovost PJ, Wachter RM, McDonald KM, Schoelles K, Dy SM Shojania K, Reston JT, Adams AS, Angood PB, et al. The top patient safety strategies that can be encouraged for adoption now. Ann Intern Med. 2013; 158(5 2):365-8.

45. Haynes AB, Weiser TG, Berry WR, Lipsitz SR, Breizat AH, Dellinger EP, Herbosa T, Joseph S, Kibatala PL, Lapitan MC, et al. A surgical safety checklist to reduce morbidity and mortality in a global population. N Engl J Med. 2009; 360(5):491-9.

46. Pronovost PJ, Goeschel CA, Colantuoni E, Watson S, Lubomski LH, Berenholtz SM, Thompson DA, Sinopoli DJ, Cosgrove S, Sexton JB, et al. Sustaining reductions in catheter related bloodstream infections in Michigan intensive care units: observational study. BMJ. 2010;340: c309.

47. Pronovost $P$, Needham D, Berenholtz S, Sinopoli D, Chu H, Cosgrove S, Sexton B, Hyzy R, Welsh R, Roth $G$, et al. An intervention to decrease catheter-related bloodstream infections in the ICU. N Engl J Med. 2006: 355(26):2725-32.

48. Luangasanatip N, Hongsuwan M, Limmathurotsakul D, Lubell $Y$, Lee AS, Harbarth S, Day NP, Graves N, Cooper BS. Comparative efficacy of interventions to promote hand hygiene in hospital: systematic review and network meta-analysis. BMJ. 2015;351:h3728.

49. Mueller SK, Sponsler KC, Kripalani S, Schnipper JL. Hospital-based medication reconciliation practices: a systematic review. Arch Intern Med. 2012;172(14):1057-69.

50. Vincent C, Burnett S, Carthey J. Safety measurement and monitoring in healthcare: a framework to guide clinical teams and healthcare organisations in maintaining safety. BMJ Qual Saf. 2014;23(8):670-7.

51. Aranaz-Andres JM, Aibar-Remon C, Limon-Ramirez R, Amarilla A, Restrepo FR, Urroz O, Sarabia O, Garcia-Corcuera LV, Terol-Garcia E, Agra-Varela Y, et al. Prevalence of adverse events in the hospitals of five Latin American countries: results of the 'Iberoamerican study of adverse Events' (IBEAS). BMJ Qual Saf. 2011;20(12):1043-51.

52. D'Amour D, Dubois CA, Tchouaket E, Clarke S, Blais R. The occurrence of adverse events potentially attributable to nursing care in medical units: cross sectional record review. Int J Nurs Stud. 2014;51(6):882-91.

53. Davis P, Lay-Yee R, Briant R, Ali W, Scott A, Schug S. Adverse events in New Zealand public hospitals I: occurrence and impact. N Z Med J. 2002;115:U271.

54. Davis P, Lay-Yee R, Briant R, Ali W, Scott A, Schug S. Adverse events in New Zealand public hospitals II: preventability and clinical context. N Z Med J. 2003;116(1183):U624.

55. Halfon P, Staines A, Burnand B. Adverse events related to hospital care: a retrospective medical records review in a Swiss hospital. Int J Qual Health Care. 2017;29(4):527-33. https://doi.org/10.1093/intqhc/mzx061.

56. Mendes W, Martins M, Rozenfeld S, Travassos C. The assessment of adverse events in hospitals in Brazil. Int J Qual Health Care. 2009:21(4):279-84.

57. Rafter N, Hickey A, Conroy RM, Condell S, O'Connor P, Vaughan D, Walsh G, Williams DJ. The Irish National Adverse Events Study (INAES): the frequency and nature of adverse events in Irish hospitals-a retrospective record review study. BMJ Qual Saf. 2017;26(2):111-9.

58. Soop M, Fryksmark U, Koster M, Haglund B. The incidence of adverse events in Swedish hospitals: a retrospective medical record review study. Int J Qual Health Care. 2009;21(4):285-91.

59. Tartaglia R, Albolino S, Bellandi T, Bianchini E, Biggeri A, Fabbro G, Bevilacqua L. Dell'erba a, Privitera G, Sommella L: [adverse events and preventable consequences: retrospective study in five large Italian hospitals]. Epidemiol Prev. 2012;36(3-4):151-61. 
60. Wilson RM, Runciman WB, Gibberd RW, Harrison BT, Newby L, Hamilton JD. The quality in Australian health care study. Med J Aust. 1995;163(9):458-71.

61. Zegers M, de Bruijne MC, Wagner C, Hoonhout LH, Waaijman R, Smits M, Hout FA, Zwaan L, Christiaans-Dingelhoff I, Timmermans DR, et al. Adverse events and potentially preventable deaths in Dutch hospitals: results of a retrospective patient record review study. Qual Saf Health Care. 2009;18(4): 297-302.

Ready to submit your research? Choose BMC and benefit from:

- fast, convenient online submission

- thorough peer review by experienced researchers in your field

- rapid publication on acceptance

- support for research data, including large and complex data types

- gold Open Access which fosters wider collaboration and increased citations

- maximum visibility for your research: over $100 \mathrm{M}$ website views per year 